

\title{
Midnight-sun-induced natural gas conversion
}

\author{
Christoph Sprung ${ }^{\mathrm{a}, *}$, Evgeniy A. Redekop ${ }^{\mathrm{b}}$, Robert D. Armstrong ${ }^{\mathrm{c}}$, Nikolaos E. Tsakoumis ${ }^{\mathrm{d}}$ \\ ${ }^{a}$ Stirnerstr. 12, 12169 Berlin, Germany \\ ${ }^{\mathrm{b}}$ Centre for Materials Science and Nanotechnology (SMN), Department of Chemistry, University of Oslo, P.O. Box 1033, Blindern, 0315 Oslo, Norway ${ }^{\mathrm{c}}$ Cardiff \\ Catalysis Institute, School of Chemistry, Cardiff University, Park Place, Cardiff CF 10 3AT, UK \\ ${ }^{d}$ Department of Chemical Engineering, Norwegian University of Science and Technology (NTNU), 7491 Trondheim, Norway
}

article info

\section{$69^{\circ}$ North}

Troms $\emptyset$, home of the worlds northernmost university may add to its list also having hosted the northernmost NGCS meeting between 5th and 9th of June 2016. The city is located $350 \mathrm{~km}$ north of the arctic circle, and the municipality counts about 75,000 inhab-itants (incl. students) one of the largest urban areas in this part of the northern hemisphere. Despite its location, the city and con-ference venue were kept free of snow and ice for the duration of the conference, thanks to continuous heat transfer from the Gulf of Mexico. The city centre, the airport, the ski jump, and most parts of Troms $\varnothing$ are situated on an island (Tromsøya), carrying around half the population of the municipality. The island is sur-rounded by a stunning panorama of snow-capped mountains. In past times, the city served as a centre for arctic hunting and start-ing point for arctic expeditions, providing experienced participants for these extreme climate conditions. Therefore, the Norwegian Polar Institute is located there. More recently Troms $\varnothing$ was a hub for explorations of oil and gas in the arctic sea.

One of the most significant buildings on mainland - Tromsø is the Arctic Cathedral, also known under its nickname Ishavskate-dralen, a modern architecture church designed by Jan Inge Hovig and completed in 1965. Its bright white colour and monumental assembly of triangular concrete templates make it one of the city's landmarks and a tourist attraction. The design for the outer shape

\footnotetext{
* Corresponding author.

E-mail address: kinetics@active-sites.de (C. Sprung).
}

of this beautiful church was adopted from nature. An island called Håja, situated north of the village of Sommarøy and easy to recog-nise by its distinct shape, inspired the architect back in the day. All conference delegates who joined the excursion on Tuesday will certainly remember seeing this island, and perhaps kept it in their photographic memory.

The local organising committee led the participants to this lat-itude of $69^{\circ}$ north to experience $24 \mathrm{~h}$ of daily daylight. Although clouds covered the blue sky and the midnight sun on most of the days, the average "southern" participant could feel the unusual quiet brightness after-hours. The meeting itself took place at the Clarion Hotel "The Edge" providing room for cutting edge scientific presentations and discussions, facilitated by local and international cuisine during lunches and coffee breaks.

\section{Bar graphs and pie charts - statistics of the conference}

In total, 279 participants from 32 nations attended the 11th NGCS meeting lasting five days between Sunday 5th and Thursday 9th of June 2016, which was hosted in Norway for the second time after the 2nd NGCS in Oslo (1990). The close interaction between academia and industry is a characteristic of this conference, with a split of $25 \%$ industrial and $75 \%$ academic participants. 141 Presenta-tions were given, including 10 keynote and 4 plenary lectures. 133 contributions were on display during two poster sessions. Three social events brought the participants together to enjoy their time in Troms $\varnothing$ in a more informal environment. Additionally, three post-symposium excursions made this meeting a memorable event for many conference delegates. 


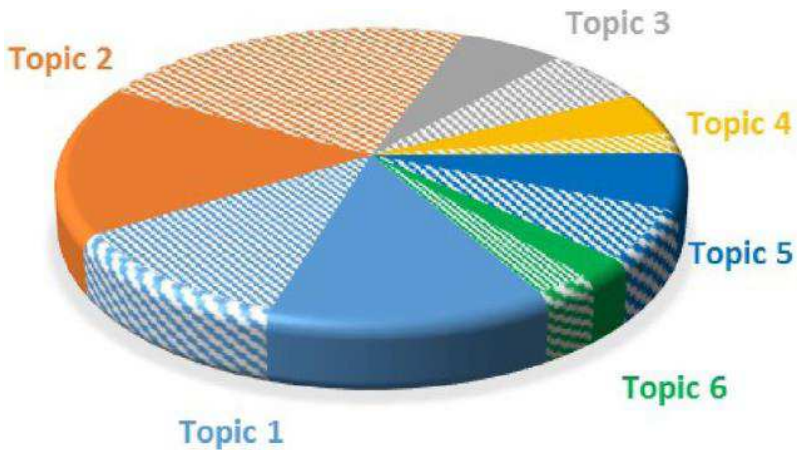

Fig. 1. Distribution of topics (named in the text) covered during NGCS 11 homo-geneous colour (oral presentation) heterogeneous colour (poster presentation) (For interpretation of the references to color in this figure legend, the reader is referred to the web version of this article.).

Six topics formed the scientific pillars of this meeting: (1) Pro-duction of Synthesis Gas, (2) Synthesis Gas to Fuels and Chemicals,

(3) Direct Conversion of Methane, (4) Conversion of Light Paraffins,

(5) Natural Gas in Energy Conversion, and (6) Techno-Economic Aspects. Their distribution amongst the oral and poster presen-tations is visualised in Fig. 1. The oral presentations and keynote lectures were subdivided into 30 sessions, with three sessions run-ning in parallel for the duration of the conference. The schedule of keynote lectures was well distributed, having none in paral-lel, thereby enabling the participants to get introduced to topics in addition to their favourite session.

Unfortunately, a number of oral presentations had to be can-celled, mainly due to strained international diplomatic relations and, therefore, missing permissions for certain researchers to travel to Norway. This unexpected turn of events reminded the partici-pants that political and immigration divides can still impede the scientific exchange in the XXI century. The organising commit-tee did a fantastic job of maintaining the schedule by filling the resulting gaps with appropriate presentations from the list of par-ticipants.

This conference was supported by The Research Council of Norway and NTNU as well as industrial partners ExxonMobil, Shell, and Haldor Topsøe.

\section{R \& D - topics covered and keynote lectures}

The symposium attracted major players in the field, from industry and academia alike, reflecting impressive efforts by the programme committee in selecting high-quality scientific contributions. The gathering provided unique opportunities for networking, forming new collaborations, and sharing of ideas. The spirit of partnership and knowledge exchange amongst the participants is very characteristic of the NGCS conference series, no matter how remote and under which climatic condition it is held. A number of outstanding contributions of this meeting will appear in a special issue of (an) appropriate journal(s) in the near future, as is a good tradition of this conference series $[1,2]$.

Each day of the conference was opened by a fascinating plenary lecture warming up the scientific brain of all participants for a fresh start to the day. All lecturers received a small gift from the organis-ers including a pair of hand-knitted traditional Norwegian gloves. A new interpretation of the common chairmans phrase "lets give the speaker a big hand".

\section{Production of Synthesis Gas Topic 1}

Topic 1 was dedicated to the overall important upstream Pro-duction of Synthesis Gas, covering in seven sessions the three major concepts of methane conversion, i.e. steam (SR) and dry (DR) reforming and partial oxidation (CPO), as well as deactivation, biosyngas, and new trends. Nickel is acknowledged as an impor-tant catalyst metal in reforming reactions due to its abundance and price. However, it is prone to coke deposition during the reaction and eventual deactivation. This issue was addressed by a large num-ber of contributions in two general ways, modification of (i) the active metal by alloying or replacing, and (ii) the support material. Modifications of active metal components focused on the intro-duction of noble metals in a pure form or alloyed with nickel, $\mathrm{Ni}-\mathrm{Co}$ alloys, and Co catalysts.

The latter group of $\mathrm{Ni}, \mathrm{Ni}-\mathrm{Co}$ and Co catalysts was compre-hensively presented in the keynote lecture by Y.-H. (Cathy) Chin (University of Toronto/Canada). She dedicated her lecture to "Cat-alytic consequences of reactive intermediates for methane dry reforming reactions on first row transition metal and alloy clusters". She compared $\mathrm{Ni}, \mathrm{NiCo}$ and Co catalysts for DR and pointed specifi-cally at their oxophilic characteristics and the resulting changes in the kinetic behaviour towards $\mathrm{CO}_{2}$ partial pressure. The increas-ing Co content shifted the initial $\mathrm{C}-\mathrm{H}$ bond activation from a metalmetal centre to metal-oxygen site pairs. The kinetically rel-evant step, however, remained the initial $\mathrm{C}-\mathrm{H}$ bond activation of methane. Others applied noble metals such as Pt or Rh to be alloyed with nickel, as well as Sm, to decrease the amount of coke deposited. The pure nickel catalyst, however, was addressed in the keynote lecture by De Chen (NTNU, Trondheim/Norway), who presented valuable insight into "Ni based steam reforming catalysts: from molecular understanding to catalyst design".

The second approach (ii), looking at the support material, has also led to significant improvements in carbon deposition and activity. The support acidity was identified to be a major issue; decreasing acidity or passivating acid sites was found to be ben-eficial, allowing processes to be run more efficiently at lower $\mathrm{O} / \mathrm{C}$ and $\mathrm{H} / \mathrm{C}$ ratios. Secondly, the ability to activate oxygen and facili-tate its mobility had a positive influence. Materials in focus were ceria, zirconia and perovskites.

According to the nature of this meeting, there were also highly industrially relevant presentations. The effectiveness of SR catalysts was addressed, presenting a shell-impregnation method, which kept the catalysts activity whilst utilising a significantly lower amount of active material for impregnation. Process economy also depends on rational heat transfer management. Heat exchangers are thereby a crucial piece of equipment and their life time signif-icantly depends on (pre)treatment conditions of the material they are made of.

Although generally termed "synthesis gas", not all mixtures of $\mathrm{H}_{2} / \mathrm{CO}$ are equally valuable for a given chemical process. The $\mathrm{H}_{2} / \mathrm{CO}$ ratio and other compositional variables depend on the feedstock and the type of conversion process. Some downstream processes require a high CO content (e.g. production of Fischer-Tropsch prod-ucts, acetic acid, and formic acid), more than could be delivered by conventional SR. By co-feeding $\mathrm{CO}_{2}$ to a SR feed (named $\mathrm{CO}_{2}$ - reforming) the $\mathrm{H}_{2} / \mathrm{CO}$ ratio can be shifted towards or slightly below one. This certainly increased the driving force of coke deposition on the catalyst. Modifications on the catalyst and support, respectively, were addressed, by the approaches mentioned above.

A session on Biosyngas focused on feedstocks other than methane for the Production of Synthesis Gas. The reforming of toluene, glycerol, and other biofuels was investigated, and the spe-cial requirements these feedstocks impose on the catalyst material were expressed. The coke deposited during these processes was certainly more severe compared to those of light hydrocarbons.

Prices of chemical resources strongly depend on their quantity, quality, and location. Low value natural gas is often associated with crude oil, appearing in low quantity, which makes its transportation less profitable. Due to the fact that it is produced as a by-product, it 
is often flared. Small scale reactor designs were presented, which are meant to utilise this (low value) natural gas and transform it into transportable liquids (e.g. methanol or others). The plants have to be tailor made and catalysts specifically designed for such small scale application.

\section{Synthesis Gas of Fuels and Chemicals Topic 2}

Topic 2 was broader and with the highest number of contri-butions covering the synthesis of higher alcohols, dimethyl ether (DME) and hydrocarbons, while a small part was devoted to methanol-to-Olefin (MTO) conversions. The extended experience of the organisers in hydrocarbon synthesis through the Fischer Tropsch (FT) reaction was reflected in the selection of oral presen-tations.

The topic included one plenary lecture (G. Jacobs Univ. of Ken-tucky, Lexington/US) and two keynotes related to Fischer Tropsch synthesis (M. Claeys, U. Cape Town/South Africa and P. Gib-son, Sasol Group Technology/South Africa) and one keynote for the synthesis of higher alcohols and DME (S. Kuld Haldor Topse A/S, Lyngby/Denmark). A number of interesting oral presenta-tions from academia and industry completed several advanced and comprehensive sessions, separated by theme. Primarily the talks concentrated on kinetic and mechanistic aspects, while cat-alyst stability was an important subject of discussion. Alternative process applications and catalytic materials were presented to a minor extent. It is worth mentioning that out of the 46 oral pre-sentations in the topic, more than $20 \%$ were given by industrial participants from companies with extensive experience in catalytic processes regarding synthesis gas conversion. These included Shell, Sasol, Johnson Matthey, Haldor Topse, Velocys, hte, Dow and Air liquide.

A well-organised plenary lecture was given by G. Jacobs (Univ. of Kentucky) presenting an overview of understanding gained by the application of synchrotron techniques over the last decades for developing insights at the atomic scale of Co based Fischer Tropsch catalysts. During his talk Gary Jacobs presented extensive kinetic and X-ray absorption studies aimed at elucidating the relation-ship between catalyst structure and performance, with particular emphasis given to the effect of promotors and deactivation mechanisms.

Both keynote lectures related to Fischer Tropsch synthesis were from South Africa. M. Claeys (U. Cape Town/South Africa) gave an overview on the "Stability of CO hydrogenation catalysts" under different conditions as studied by a unique in situ magnetometer that can accommodate realistic reaction conditions that are often met in industrial sites. The set-up has been developed in close col-laboration with Sasol Technology. Iron and cobalt catalysts were the focus of research and oxidation, carbide formation and sintering phenomena were analysed and presented. In a step further the keynote lecture by P. Gibson (Sasol Group Technology/South Africa) "Development of commercial cobalt type Fischer-Tropsch catalysts" summarised recent understanding in FTS from Sasols perspective and the application of acquired knowledge into rational design for catalyst development. The optimisation of a carbon-coated silica-alumina supported Co catalyst in terms of activity and stability was described.

On the theme of methanol and dimethyl ether synthesis S. Kuld (Haldor Topsøe A/S, Lyngby/ Denmark) gave a keynote lecture speaking about the "Roles of $\mathrm{ZnO}$ in methanol and methanol-dimethyl ether-combi catalysts". Attention was given to the opposite behaviour of $\mathrm{Zn}$ regarding formation of methanol and DME. In particular, although the $\mathrm{Cu}-\mathrm{Zn}$ synergy through surface alloying boosts methanol synthesis, $\mathrm{ZnO}$ poisons DME formation on methanol-DME bi-functional catalysts.

\section{Direct Conversion of Methane Topic 3}

Topic 3 dealt with the conversion of methane directly to valu-able molecules, rather than converting it via the syngas route (see Topic 1). A crucial step is to achieve the initial $\mathrm{C}-\mathrm{H}$ activation of the highly symmetric methane molecule, while minimising the formation of coke and complete oxidation. Selectivity of methane conversion into acetylene, ethane, benzene, methanol, formalde-hyde, and other desired molecules was discussed in Topic 3.

A focus was set on developments in plasma processes, which facilitate heat and energy transfer for the crucial methane activa-tion step and, hence, could increase conversion and yield. Plasma processes were tested with and without catalytic material present. The effect of a catalyst was still found to be beneficial. D.H. Lee (Korea Institute of Machinery and Materials, Daejeon/Republic of Korea) dedicated his keynote lecture to "Effective Plasma Process for Methane direct conversion", presenting a rotating arc technology. Depending on the input energy through the plasma, very good yields of acetylene could be achieved. This process may open a promising new route in the field of direct methane utilisation. Acetylene is a valuable intermediate for (amongst others) the for-mation of unsaturated $\mathrm{C}_{4}$ hydrocarbons.

OCM an everlasting, certainly interesting, topic suffering from low yields due to over-oxidation, was presented in new light with improved performance. The introduction of an electric field over polyoxometalate catalysts lowered the reaction tempera-ture and increased the yield of $\mathrm{C}_{2}$ products. Higher hydrocarbons were produced in a dual reactor concept feeding $\mathrm{CH}_{4}$ and $\mathrm{CO}_{\mathrm{X}}$ over Fe-catalysts. The oxygen transfer and its mobility are a crucial parameter for OCM reactions. Therefore, a chemical loop-ing concept applying oxygen storage materials was presented. Further insight into surface oxygen species was gained by the investigation of reduction and oxidation characteristics. Different oxygen species, both short and long lived, were distinguishable by their ability to form total oxidation and OCM products respec-tively.

The direct formation of methanol, formaldehyde, ethane, and aromatics formed another session. Two major points of inter-est were presented (i) the increase of yield and selectivity, and (ii) the decrease of coke formation and deposition. The former issue was addressed by a membrane reactor concept, in which the generated hydrogen was separated from the reactant/product stream, increasing the yield of aromatics. For the production of formaldehyde, co-feeding of nitrogen oxides was found to be beneficial, favouring $\mathrm{NO}_{2}$. Photocatalytic approaches were also pre-sented, addressing the improved yield and selectivity to ethane from methane over noble metal-promoted gallium oxide. Coke for-mation and deposition is a significant issue in any hydrocarbon processing reaction and its limitation desired. Zeolite materials in the presented experiments showed different coke formation mech-anisms on inner and outer surfaces. Furthermore, the influence of regeneration on the characteristics of the material (e.g. pore vol-ume) was addressed. In a oneand two-stage fluidised bed reactor regime, continuous catalyst regeneration was realised and stable performance ensured.

A plenary lecture for Topic 3 was presented on Wednesday morning by the awardee Xinhe Bao (Dalian Institute of Chemi-cal Physics / Chinese Academy of Sciene) with the shortest title of all plenaries "New horizons in $\mathrm{C}_{1}$ chemistry" (Fig. 2), with this, however, covering a tremendous scope of topics in this field. He combined in his presentation in a very original manner both scien-tific details and industrially relevant results. Enrapt until the end, Xinhe Bao succeeded in further piquing the interests of delegates with a slide of unpublished data on his groups OX-ZEO systems. High yields of; ethylene, aromatics or heavier liquid hydrocarbons were reported upon switching of the zeolite component of these 


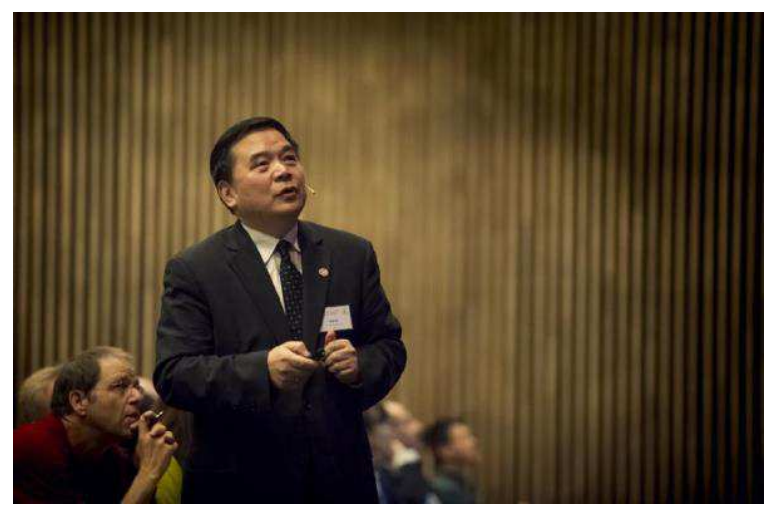

Fig. 2. Xinhe Bao (Dalian Institute of Chemical Physics/Chinese Academy of Science) during his plenary/award lecture "New Horizons of $\mathrm{C}_{1}$ Chemsitry".

physically mixed catalyst beds. One to look out for at NGCS 12 , in three years time.

\section{Conversion of Light Paraffins Topic 4}

Presentations in Topic 4 covered a wide range of processes and catalysts for the conversion of $\mathrm{C}_{2}-\mathrm{C}_{4}$ alkanes from NG (natural gas) into alkenes, alcohols, and other value-added chemicals. Several presentations focused on different aspects of oxidative and non-oxidative alkane dehydrogenation processes, including practical reactor design. Echoing the message of the first plenary lecture of this meeting by Jim Rekoske (Vice Precident \& Chief Technology Officer at UOP/USA), the reported results reaffirmed the growing importance and technological maturity of alkane dehydrogenation as a way to produce pure on-purpose light alkenes.

In his keynote lecture on Wednesday with the title "Selective $\mathrm{C}-\mathrm{H}$ Bond Activation by Supported $\mathrm{Pt}_{1} \mathrm{Zn}_{1}$ Nanoparticle Alloys dur-ing the Catalytic Dehydrogenation of Ethane", Fabio. H. Ribeiro (Purdue University, West Lafayette/USA) shared the latest fun-damental findings regarding $\mathrm{C}-\mathrm{H}$ bond activation on bimetallic catalysts. Fabio Ribeiro highlighted the catalytic properties of alloyed PtZn nanoparticles for ethane dehydrogenation that were recently elucidated with advanced experimental and theoretical methods by he and his co-authors.

Catalytic partial oxidation of alkanes into oxygenates was the other major focus of presentations in Topic 4, with an emphasis on MoV-based mixed oxide catalysts as well as methanol produc-tion from methane on $\mathrm{Cu}$ - and $\mathrm{Fe}$ substituted zeolites. Christoph Sprung presented a highly innovative kinetic analysis of propane oxidation into acrylic acid over the Mo-V-Te-Nb-O catalyst. The kinetics of this complex reaction exhibited several hierarchical time scales which may provide the kinetic signatures for differ-ent active sites that mediate independent reaction routes. Novel results for NG upgrading were also presented in Topic 4 about oxychlorination and alkene oligomerization reactions. Unlike other contributions in this topic that dealt predominantly with catalytic kinetics, the presentation by Evgeniy Redekop emphasised the importance of transport processes for understanding the catalytic reactions involved in Natural Gas processing. Specifically, his talk focused on the use of diffusional transport inside the Temporal Analysis of Products (TAP) microreactor for exploring transport-kinetics interactions in zeolitic catalysts for Methanol-to-Olefins (MTO) conversions.

Unni Olsbye (University of Oslo/Norway) had no problem attracting a full audience for the final plenary lecture of this conference on Thursday morning after the conference dinner, enti-tled "MTH revisited, status and prospects from fundamental". She opened her lecture by recalling a now anecdotal encounter at her first NGCS symposium in 1990. Then a graduate student, she was about to deliver her first presentation at an international scien-tific meeting when she was mistaken by one of the conference's participants for a waitress because young female scientists rarely delivered speeches at academic meetings in those days. She noted that the gender balance within the field has improved since that memorable first talk at NGCS, but more efforts are needed to progress further. In the inspiring and energetic one-hour lecture that followed, Unni Olsbye outlined the state-of-the-art in zeolite-catalysed Methanol-ToHydrocarbon (MTH) chemistry and shared the cutting edge results obtained in her group regarding the intri-cate reaction mechanisms that drive this promising industrial route to sustainable hydrocarbons. She presented novel understanding of the differences between methanol and dimethyl ether as the source of methyl groups for building larger MTO products inside shapeselective zeolites. She also discussed exciting new results obtained in the study of catalyst deactivation, which may pave way for improved industrial MTO processes.

\section{Natural Gas in Energy Conversion Topic 5}

Topic 5 covered processes relating to natural gas as an energy resource. With anthropogenic $\mathrm{CO}_{2}$ emissions implicated in ever-increasing atmospheric $\mathrm{CO}_{2}$ levels, recently exceeding $400 \mathrm{ppm}$, flue gases clearly present both a problem and potential resource. Apt then that Topic 5 opened with a keynote talk by A.-C. Roger (ICPEES, U Strasbourg/France) titled "Development of methanation catalysts for the process chain power to gas." She reported the remarkable activity of their co-precipitation prepared $10 \mathrm{wt} . \% \mathrm{Ni} /$ ceriazirconia-praseodymia in the catalytic methana-tion of $\mathrm{CO} / \mathrm{CO}_{2}$, with conversion approaching the thermodynamic limit. Two key themes ran through sessions in Topic 5; Syn-thetic Natural gas production via the Sabatier Reaction and the derivation of high purity hydrogen through methane reform-ing over mixed oxide and carbon supported catalysts. Perhaps unsurprisingly, several talks addressed the activity and stabil-ity of Ni-based catalysts under $\mathrm{CO}_{2}$ hydrogenation conditions. In contrast, Michael Claeys presented the novel ability of $\mathrm{K}$ doped iron-based Fischer-Tropsch catalysts to catalyse the hydrogena-tion of $\mathrm{CO}_{2}$, proceeding via consecutive WGS and FT reactions. The group combined in situ XRD and novel magnetometry techniques to study the reversible conversion of $\mathrm{Fe}(0)$ to Hägg carbide under reaction conditions and identify the role of potassium dopants.

\section{Techno-Economic Aspects Topic 6}

Addressing both technical and economic aspects of NG pro-cesses, Topic 6 satisfied the NGCS practice in bringing together both academic and industrial interests. A broad scope was covered dur-ing these two sessions, with presentations on natural gas refining (removal of $\mathrm{Hg}$ and $\mathrm{H}_{2} \mathrm{~S}$ ) and process development (for GTL and OCM).

Jim Rokoske (Vice President \& Chief Technology Officer at UOP/USA) was honoured with the pleasure to give the first ple-nary lecture of the conference, related to this topic. He presented "Technoeconomic impacts of abundant natural gas liquids on the chemical industry". This plenary began with a comprehensive overview of stranded feedstocks, an issue close to the heart of the Norwegian natural gas community.

During his keynote lecture on Tuesday titled "Techno-economic analysis of individual and integrated oxidative coupling of methane processes" H.R. Godini (TU Berlin/UniCat BASF, Berlin/Germany) provided an overview of recent advances in catalytic OCM pro-cess. Particular emphasis was given to maximising potential cost/energy savings versus alternate ethylene synthesis routes. 
An extensive study was presented into the effect which oper-ating temperature and $\mathrm{CH}_{4} / \mathrm{O}_{2}$ ratios have on the performance of supported oxide catalysts in the OCM reaction, in particular $\mathrm{La}_{2} \mathrm{O}_{3}-\mathrm{SrO}_{7} / \mathrm{CaO}$. The importance of a high methane to oxygen ratio in achieving appreciable $\mathrm{C}_{2}$ (ethane/ethene) selectivities was highlighted.

\section{Gas Hydrates, new concepts}

Jürgen Mienert is a professor at the local University of Troms (UiT) and presented a keynote lecture on the "Arctic gas hydrates as unconventional energy". Gas hydrates (first discovered in the permafrost regions of Russia) are crystalline, ice-like compounds, which trap biogenic and/or thermogenic gases in a lattice of water. Their appearance is governed by the complex interplay between pressure, temperature, and amounts of gas and water available. One part of this research is to understand the mobility and dynamic of gas hydrate reservoirs and how they may practically be pro-duced and used as an energy resource. The challenges of this topic are revealed in the published estimates of stored methane in gas hydrates, which range from several hundred to tens of thousands of Gts. Certainly, the gained knowledge and experience from the pro-duction of natural gas and crude oil are a valuable starting point for the exploration of gas hydrates for commercial use.

\section{Get together at the social events}

The welcome reception of this conference was held in the worlds northernmost aquarium, the Polaria. Conference delegates could enjoy a tasty Sushi meal while greeting fellow NGCS partici-pants and watching bearded seals. Its modern architecture building (opened in 1998) resembles ice floats, which were pressed onto land by rough Artic Seas. The museum also houses live animals and plants of the most common species in the Barents Sea. Movies about the fascinating nature and climate of the Arctic Sea were presented in the panoramic cinema.

A sweater and windproof jacket were required for Tuesdays trip to the fishing village of Sommarøy, which is situated west of Troms $\varnothing$, open to the Arctic Sea. This place is known for its beau-tiful sandy beaches and clear water. The bus ride of about $1.5 \mathrm{~h}$ along the southern coastline of a large island called Kvaløya, pro-vided scenic views of mountains, islands, and typically colourful Norwegian wooden houses set into the rugged surroundings. A lovely dinner buffet was provided in a fishing warehouse, serv-ing amongst other things traditional (and very tasty) fish soup and whale meat from the BBQ. For those, who had not yet experienced enough of Norwegian life and culture, the organisers themselves led brave participants for a swim in the Arctic Sea (probably inspired by Jürgen Mienerts keynote lecture on arctic gas hydrates ear-lier that day). The swimming opportunity seemed independent of gender, nationality and research interest the water had the same temperature for everyone. All swimmers returned safely to shore, de-icing in a dry towel to the applause of those who had forgotten their own swimming suits. The evening continued with network-ing, drinks, and singing along with our host (the Fisherman) and his guitar. Many also took the opportunity for a walk around Som-marøya, experiencing the cosy quiet atmosphere of this village and beautiful scenery of sandy beaches and small islands surrounding it.

The highlight of every conference proves to be the Gala Dinner, for NGCS 11 celebrated in the Clarion Hotel "The Edge" on Wednes-day evening. Grouped on round tables, the participants could enjoy a delicious four-course meal. Krijn de Jong (Utrecht University/The Netherlands), currently the chair of the Natural Gas Conversion Board (NGCB), gave a short speech, thanking the organisers for the

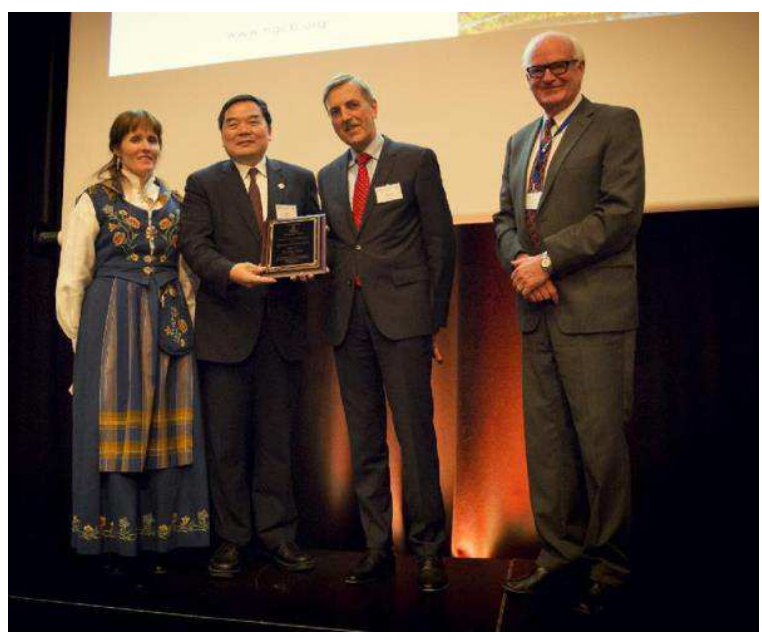

Fig. 3. Ceremony for the 2016 Award for Excellence in Natural Gas Conversion given to Xinhe Bao (centre left, Dalian Institute of Chemical Physics/Chinese Academy of Science), accompanied by Hilde Venvik and Anders Holmen (left and right, respec-tively, NTNU Trondheim/Norway, representing the organising committee of NGCS 11) and Krijn de Jong (centre right, Utrecht University/The Netherlands, representing the NGCB).

excellent conference and their effort and enthusiasm in turning the 11th NGCS meeting into a success for everyone.

The scientific highlight of this Natural Gas Conversion Sympo-sium was the announcement of the 2016 Award for Excellence in Natural Gas Conversion for Xinhe Bao (Dalian Institute of Chemical physics/Chinese Academy of Science Fig. 3). He is recognised for his contributions of fundamental understanding of the chemistry and engineering of gas conversion, combining theory, model catalysts, and technical catalysis in a very original manner. Three topics of his work shall be emphasised (i) Direct Conversion of Methane to Aromatics, (ii) CO hydrogenation to fuels and chemicals, and (iii) Direct Conversion of Methane to Lower Olefins. His contributions led to breakthrough developments in both academic and industrial sciences.

The 2016 Award for Excellence in Natural Gas Conversion con-tinues the high level of research and development recognised by this award, formerly presented to Krijn de Jong (2013), Anders Hol-men (2010), David Trimm (2007), Enrique Iglesia (2004), Lanny Schmidt (2001), Jens Rostrup-Nielsen (1998), and Jack Lunsford (1993). And now (dear reader) close your eyes and feel the power of research expressed by this list of awardees.

Two poster prizes were awarded to Anaelle Paredes-Nunez (IRCELYONUniversite Lyon 1/France) and Evgenii V. Kondratenko (Leibnitz Institute for Catalysis, Rostock/Germany) for their contribution during Tuesdays and Wednesdays poster session, respectively (see Fig. 4). The committee acknowledged the clear layout of both posters combined with a high scientific level and an enthusiastic presentation allowing detailed and high level scientific discussion. A. Paredes-Nunez presented her poster in Topic 2 with the title "Determination of the most active sites for CO hydrogena-tion over supported cobalt by selective poisoning with tin". E.V. Kondratenko contributed to Topic 4 with his poster on "Kinetic and Mechanistic Aspects of Dehydrogenation of Propane and Isobutane Elucidated by High-Throughput Tools".

Two more surprises were about to come during this confer-ence dinner. One, of course, was expected, the announcement of the location for the next NGCS meeting in 2019. Fabio H. Ribeiro (Purdue U, West Lafayette/USA) had the honour to present San Antonio/TX, USA for this occasion. Later on, Claude Mirodatos (IRCELYON/France) took the stage to prove once more how well science and music fit together. His musical skills could already be 


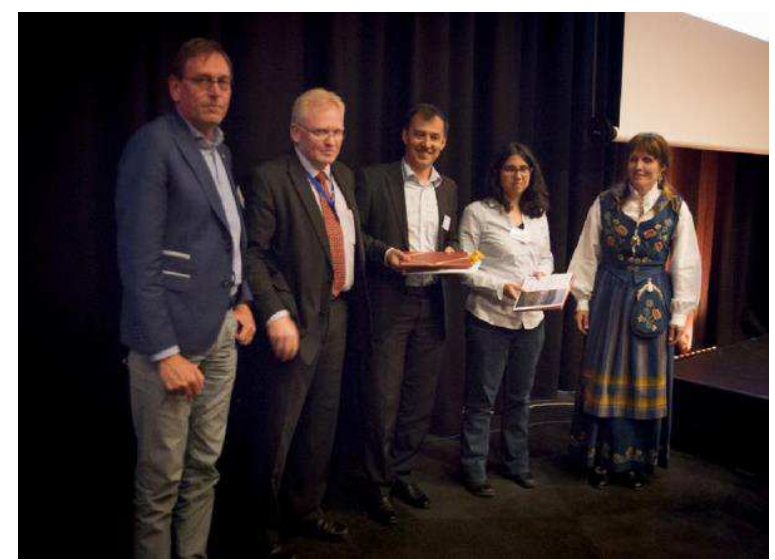

Fig. 4. Poster award for E.V. Kondratenko (centre, Leibnitz Institute for Catalysis, Rostock/Germany) and A. Paredes-Nunez (centre right, IRCELYON Universit Lyon 1/France) accompanied by Heiko Oosterbeek (left, Shell/The Netherlands) and Edd A. Blekkan (centre left, NTNU Trondheim/Norway) (representing the selection com-mittee) and Hilde Venvik (right, NTNU Trondheim/Norway, dressed in a traditional Norwegian folk costume called Bunad, representing the organising committee of NGCS 11).

enjoyed during (his) NGCS 9 in Lyon in 2010. He presented a self-written song "Thank you dear organisers", which was joyfully sung by the audience in the style of a canon.

\section{Rubber Boots, Kvikk Lunsj, and Red Helmets - The Post- Symposium Programme}

The organisers offered a great variety of post-conference excur-sions between sea level and mountain top.

\section{Boat fishing excursion 9th of June}

A group of 30 NGCS participants boarded the N/S Caroline Mathilde, a classic wooden motorsailer built in 1939 . The weather was chilly and cloudy with a light breeze of $8 \mathrm{~km} / \mathrm{h}$ coming from Northwest. As soon as the bowlines where cast off, the captain wel-comed all passengers aboard and headed south towards his fishing spots in the fjord. On the way most of the participants remained on deck, enjoying the unusual scenery and panorama of snow-capped mountains on this bright Norwegian summer evening.

With the lines cast, some of the participants lines had "nibbles," but despite their best efforts there were not any large catches. For the yarn, a small cod was caught whilst a smaller cod did not want to stay aboard, returning to sea of its own volition. Despite the low fishing efficiency there was some chemistry on board and peo-ple kept catching each others hooks (literally and metaphorically). True to the spirit of fishing, this lack of catching gave participants the opportunity to get to know one each other, particularly dur-ing the line untangling process. The brave and patient kept fishing whilst the rest were mingling in the cabin. The refreshing wind kept blowing, keeping fishermen awake and feeding their appetites. Fortunately, the friendly crew offered wine and warming beverages, while later on a delicious Norwegian style salmon soup was served. After a couple of hours, the crew made their voyage back to the small harbour in Troms $\emptyset$ under the same weather conditions as their outward journey.

\section{Mountain hike 9th of June}

The hiking trip up the $784 \mathrm{~m}$ Kjølen mountain outside Troms $\varnothing$ was truly a highlight of post-conference activities. Hilde Venvik (NTNU Trondheim/Norway) grew up in a small town nearby and knew the mountain path like the back of her hand. She and her mother Inga Venvik led the group of more than a dozen partic-ipants on a 6-h hike to the top of the mountain, all the while sharing their knowledge of the sparse local flora and their deep admiration for this beautiful and rugged northern land. "In the past, those industrial-looking steel tanks on the other side of the water were used to store enormous quantities of whale fat - then a com-mon lamp fuel in Norway" narrated Inga, as the group walked along the mountain ridge and enjoyed stunning views of the land-scape. In the context of the conference, these memories of the past inspired very relevant, yet also troubling thoughts about the his-tory of resource consumption and human relationships with the environment. Transition from traditional hydrocarbon sources to renewables will be, by far, more challenging than the transition from whale oil to crude oil and natural gas. Surmounting snow-covered rocky peaks together provided a perfect allegory for this difficult task which, as the conference demonstrated, can be accom-plished only through the integrated multidisciplinary efforts of scientists, engineers, and industrialists. The joy and success of these multidisciplinary efforts are nicely documented by the smiling faces in Fig. 5 taken on the way to the top of the Kjølen mountain.

\section{Snøhvit LNG site visit in Hammerfest 9th-10th of June}

A group of eleven participants signed up for the exciting excursion to Hammerfest, who already started gathering at lunch time that day to get to know each other and the tour guide Ljubisa Gavrilovic (NTNU, Trondheim/Norway). Departing in the late

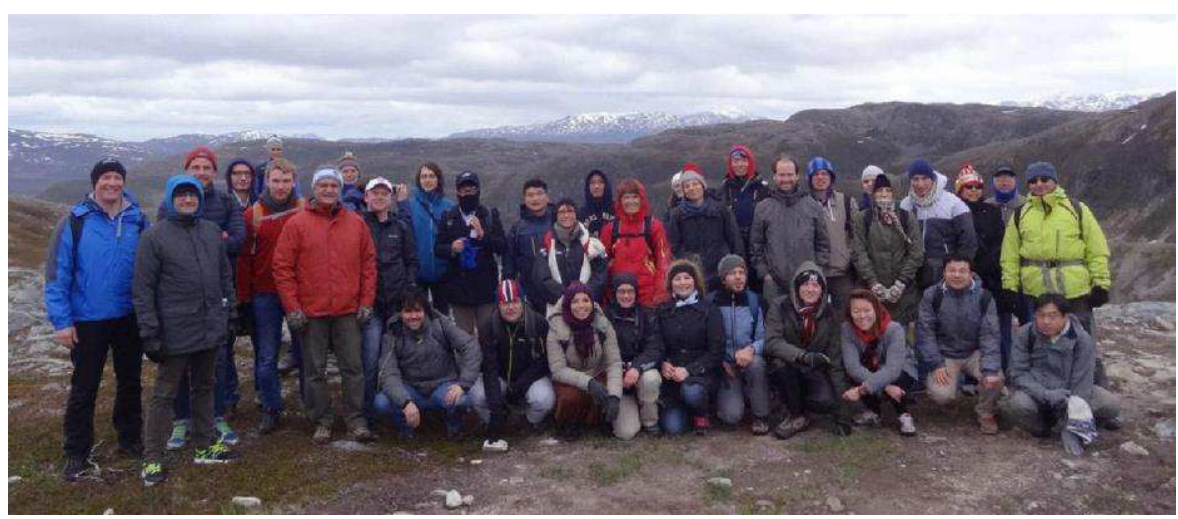

Fig. 5. Group picture en route to summiting the $784 \mathrm{~m}$ Kjølen mountain near Troms $\varnothing$. 


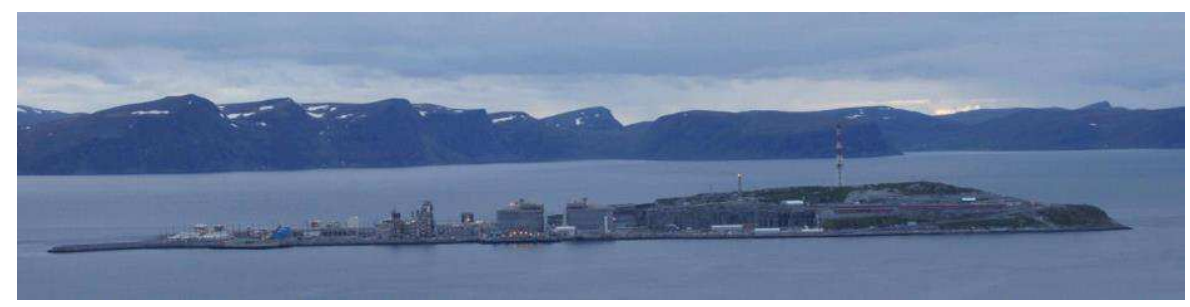

Fig. 6. Statoil LNG site at Melkaøya.

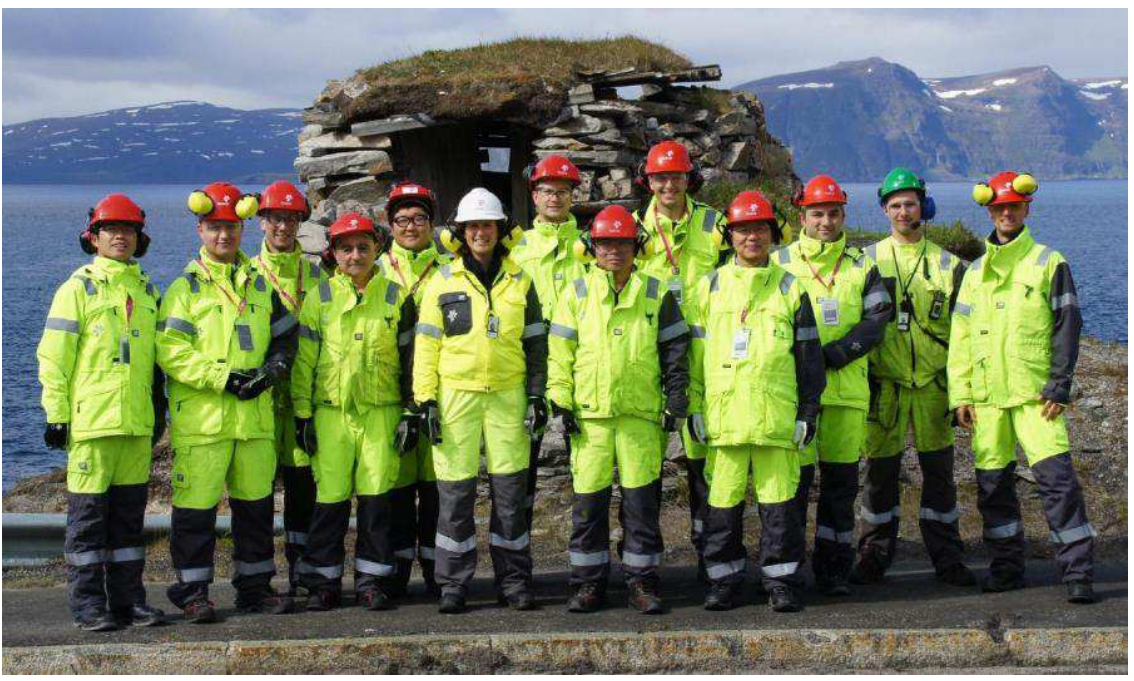

Fig. 7. Group picture at Melkaøya after LNG site visit.

afternoon from Troms $\varnothing$ airport, the group was looking forward to get to know the north.

Same light, fewer people - Hammerfest a town of about 10,000 inhabitants is largely built along the coast line of a natural habour. Rocky hills left some space to build the city, which invites would-be visitors for hiking and reindeer watching. The city was the first urban settlement in Northern Europe which got electrical street lighting in 1891 and is home to the Royal and Ancient Polar Bear Society, offering arctic hunting and expeditions in Hammerfest.

The excursion to the LNG site started the next day. Equipped with visitorbadges, keeping in mind their personal entrance code, the group reached the island of Melkøya (Fig. 6) through the sup-ply tunnel. Ragnhild Rønning, the local tour guide, welcomed the participants on the other side.

The visit started off with viewing a number of miniature mod-els of the LNG site at Melkøya, the ship "Arctic Lady" carrying LNG across the ocean, and the subsea templates anchored at the bot-tom of the sea, which connect the underground natural gas with the outside world. The number of (allowed) pictures taken of the provided exhibits and questions passed on to our local tour guide expressed the enthusiasm and interest of the participants. Subsequently, the group was given a presentation covering all facts about the history, development, and technical details of the site. It has an annual production of about 4.3 Mt LNG, for which it requires (just) $190 \mathrm{MW}$ of energy for liquefaction, making it one of the most energy efficient and environmentally friendly LNG plants in the world. The group kept its impression, taken from the first part of the tour, and continued interacting with its local guide to get even more informa-tion than the slides provided. It seemed already at this point, that the participants were glad to have signed up for this trip very very interesting indeed and another highlight was still to come. Time flies when you are having fun (they say), and the group had to get going for the walk through the site, to make it back in time for lunch. Everyone got dressed in shiny yellow jackets and trousers, proper boots, gloves, goggles, and red helmets (see Fig. 7 - we were safe!). The tour began, walking through the site surrounded by artificial walls of massive rocks standing firm against the waves. Seeing the pipes delivering the natural gas from the Snøhvit field $143 \mathrm{~km}$ off shore entering the complex installation at Melkøya.

One of the most impressive parts was certainly "the barge", the heart of the site, which contains the equipment for liquefication and distillation placed on a $154 \mathrm{~m} \times 54 \mathrm{~m} \times 9 \mathrm{~m}$ barge, shipped in from its construction site in southern Spain in one piece all the way to Hammerfest multilevel high performance engineering. The walking tour finished with a brief view of the LNG, LPG, and con-densate tanks and the jetty from which they are loaded and shipped to destinations around the world.

The last part of the visit was a tasty lunch at the canteen, which introduced some of the participants to a bit of traditional Norwe-gian food (if they have not yet taken the opportunity to taste some lovely waffles with brown cheese during the conference week in Troms $\emptyset$ ). Finally, all participants could take a personal copy of the book "Snøhvit" with them, telling the history and development of the site. Tusen Takk StatOil and Ragnhild Rønning for the fantastic and memorable visit on Melkøya!

\section{Outlook NGCS 12 in San Antonio/USA 2019}

The triennial NGCS meeting continues in 2019 in San Antonio, TX/USA. Temperatures and climatic conditions will be totally differ-ent from the past symposium in Troms $\varnothing$, changing from subarctic to humid subtropical. Both places, however, are connected to each other. The distance of about $6840 \mathrm{~km}$ between them could well be 
covered following the untiring Gulf Stream and its northern branch, the North Atlantic Drift, in the opposite direction. "The-stream", the core of the NGCS meetings, covering up- and down-stream pro-cesses of natural gas conversion. The organising committee, will be headed by Fabio H. Ribeiro (Purdue U, West Lafayette/USA) and is looking forward to welcoming bright minds presenting great science and developments three years from now.

\section{References}

[1] (a) Appl. Catal. B: Environ. 113-114 (2012) 1-326;

(b) Catal. Today 171 (2011) 1-312;

(c) Chem. Eng. Sci. 66 (2011) 6307-6560

[2] (a) Catal. Today 228 (2014) 1-218;

(b) Ind. Eng. Chem. Res. 53 (2014) 1719-2072. 